\begin{tabular}{|c|l|}
\hline Title & Transfer hydrogenation of cellulose to sugar al cohols over supported ruthenium catalysts \\
\hline Author(s) & Kobay ashi, Hirokazu; Matsuhashi, Hisateru; Komanoya, Tasuku; Hara, Kenji; Fukuoka, A tsushi \\
\hline Citation & $\begin{array}{l}\text { Chemical Communications, 47(8), 2366-2368 } \\
\text { https:/doi.org/40.1039/c0c043119 }\end{array}$ \\
\hline Issue Date & 2011-02-28 \\
\hline Doc URL & http://hdl.handle.net/2115/47501 \\
\hline Rights & Chem. Commun., 2011, 47, 2366-2368- Reproduced by permission of The Royal Society of Chemistry (RSC) \\
\hline Type & article (author version) \\
\hline File Information & CC47-8_2366-2368.pdf \\
\hline
\end{tabular}

Instructions for use 


\title{
Transfer hydrogenation of cellulose to sugar alcohols over supported ruthenium catalysts
}

\author{
Hirokazu Kobayashi, ${ }^{a}$ Hisateru Matsuhashi, ${ }^{a}$ Tasuku Komanoya, ${ }^{a b}$ Kenji Hara ${ }^{a}$ and Atsushi Fukuoka ${ }^{a}$ \\ Received (in $X X X, X X X) X$ th $X X X X X X X X X 200 X$, Accepted $X$ th $X X X X X X X X X 200 X$ \\ ${ }_{5}$ First published on the web $X$ th $X X X X X X X X X 200 X$ \\ DOI: 10.1039/b000000x
}

$\mathrm{Ru} / \mathrm{C}$ catalysts are active for the conversion of cellulose using 2propanol or $\mathrm{H}_{2}$ of $0.8 \mathrm{MPa}$ as sources of hydrogen, whereas $\mathrm{Ru} / \mathrm{Al}_{2} \mathrm{O}_{3}$ catalyst is inactive in both reactions, indicating that the ${ }_{10} \mathrm{Ru} / \mathrm{C}$ catalysts are remarkably effective for the cellulose conversion.

The conversion of renewable biomass to useful chemicals is one of the most important goals in green and sustainable chemistry. ${ }^{1}$ In order to avoid competition with food 15 production, as seen in the last few years, non-food biomass should be used as a biomass resource for the manufacture of chemicals. Cellulose is the most abundant non-food biomass resource produced via photosynthesis, ${ }^{2}$ and therefore the conversion of cellulose has attracted significant attention as a 20 key issue in the utilisation of biomass. ${ }^{3}$ Cellulose is a waterinsoluble polymer composed of glucose units linked by $\beta-1,4-$ glycosidic bonds, ${ }^{2,4}$ and the hydrolysis-hydrogenation (abbreviated as hydrogenation) of cellulose gives sugar alcohols, which are versatile precursors to plastics, fuels and ${ }_{25}$ pharmaceuticals. Therefore, sugar alcohols are among the major targets in the transformation of cellulosic biomasses.

Since we reported the conversion of cellulose to sorbitol and mannitol by supported $\mathrm{Pt}$ and $\mathrm{Ru}$ catalysts under $\mathrm{H}_{2}$ pressure, ${ }^{5}$ other groups have also reported the degradation of 30 cellulose to sorbitol $^{6}$ or ethylene glycol $^{7}$ using various supported metal catalysts under high pressures of $\mathrm{H}_{2}(\geq 5$ $\mathrm{MPa}$ ). These solid catalysts have the advantage of easy separation and produce the desired chemicals in good yields under aqueous conditions. However, one of their 35 disadvantages is the need for pressurised $\mathrm{H}_{2}$. As an alternative to $\mathrm{H}_{2}$ pressure, we investigated the transfer hydrogenation of cellulose using an alcohol and found that sugar alcohols are obtained as major products using the carbon-supported $\mathrm{Ru}$ catalysts (Scheme 1). To the best of our knowledge, the 40 transfer hydrogenation of cellulose using heterogeneous catalysts has not previously been reported.

Table 1 summarises the results of the transfer hydrogenation of cellulose by various supported Ru catalysts using 2-propanol as a source of hydrogen without bases.

${ }_{45}$ Among the catalysts, the Ru/carbons [Ru/AC(N), Ru/C-Q10 and $\mathrm{Ru} / \mathrm{CMK}-3$ ] gave the highest yields of sugar alcohols (entries 3, 8, 9). For example, the yields in the reaction using $\mathrm{Ru} / \mathrm{C}-\mathrm{Q} 10$ were $37 \%$ sorbitol and $9.0 \%$ mannitol for a total of $46 \%(0.87 \mathrm{mmol})$. The turnover number (TON) based on bulk ${ }_{50} \mathrm{Ru}(0.01 \mathrm{mmol})$ for the sum of the sugar alcohols was 87 . The conversion of cellulose was $80 \%$, which was determined from the weight difference of the solid after the reaction.

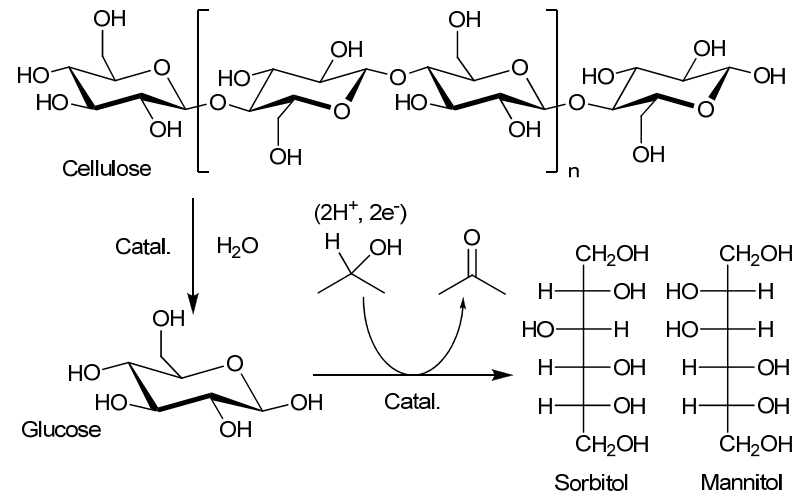

Scheme 1 Transfer hydrogenation of cellulose to sugar alcohols.

55 Accordingly, the selectivity based on the cellulose conversion for the sum of the sugar alcohols was 57\%. 1,4-Sorbitan (1.4\%), $\mathrm{C}_{2}-\mathrm{C}_{4}$ polyols (total 5.3\%: ethylene glycol $0.8 \%$, propylene glycol $1.8 \%$, glycerine $1.2 \%$ and erythritol $1.5 \%$ ), and glucose $(0.7 \%)$ were produced as minor products. As the 60 source of hydrogen, $15 \%$ of 2-propanol (20 mmol) was converted to acetone, which was 22 times as much as the yield of the sugar alcohols $(0.87 \mathrm{mmol})$. Thus, only $4.5 \%$ of the hydrogen species was utilised for the production of the sugar alcohols and the other part evolved as $\mathrm{H}_{2}$ gas during the 65 reaction (see below). Ru/AC(W) (sugar alcohol yield 23\%), $\mathrm{Ru} / \mathrm{BP} 2000$ (14\%) and Ru/XC72 (3.0\%) were less active than $\mathrm{Ru} / \mathrm{AC}(\mathrm{N}), \mathrm{Ru} / \mathrm{C}-\mathrm{Q} 10$ and $\mathrm{Ru} / \mathrm{CMK}-3$ (entries 7, 10, 11). $\mathrm{Ru} / \mathrm{TiO}_{2}, \mathrm{Ru} / \mathrm{ZrO}_{2}$ and $\mathrm{Ru} / \mathrm{Al}_{2} \mathrm{O}_{3}$ were inactive for the reaction (entries 12-14), which indicates that the catalytic activity of ${ }_{70} \mathrm{Ru}$ greatly depends on the supports. It is notable that $\mathrm{Ru} / \mathrm{Al}_{2} \mathrm{O}_{3}$ is an active catalyst for the hydrogenation of cellulose to sugar alcohols using $\mathrm{H}_{2}$ gas of $5 \mathrm{MPa},{ }^{5}$ while it is completely inactive for the transfer hydrogenation (entry 14). Thus, we suggest that the active Ru species in this transfer 75 hydrogenation is different from that in the typical hydrogenation reaction with $\mathrm{H}_{2}$. In the reactions using the inactive catalysts (entries 12-14), glucose and 5hydroxymethylfurfural (5-HMF) formed instead of the hydrogenated products with almost no conversion of 280 propanol. This is the same tendency as in the reactions without $\mathrm{Ru}$ catalysts (entries 1, 2), indicating that the hydrolysis of cellulose to glucose proceeds with or without catalysts $^{6 a, 8-10}$ and that an active $\mathrm{Ru}$ species hydrogenates glucose to the sugar alcohols using a hydrogen species derived ${ }_{85}$ from 2-propanol. Carbon-supported Rh, Ir, Pd, Pt and Au catalysts were also tested for the reaction (entries 16-20), but the sugar alcohols were not obtained. Therefore, we chose 
Table 1 Transfer hydrogenation of cellulose by supported metal catalysts. ${ }^{a}$

\begin{tabular}{|c|c|c|c|c|c|c|c|c|c|c|c|}
\hline \multirow[t]{2}{*}{ Entry } & \multirow[t]{2}{*}{ Catalyst } & \multicolumn{8}{|c|}{ Yield based on carbon /\% } & \multirow{2}{*}{$\begin{array}{l}\text { Cellulose } \\
\text { conv. }^{e} / \%\end{array}$} & \multirow{2}{*}{$\begin{array}{c}\text { Yield of } \\
\text { acetone } / \%\end{array}$} \\
\hline & & Sorbitol & Mannitol & $\begin{array}{c}\text { Sum of sorbitol } \\
\text { and mannitol }\end{array}$ & Sorbitan & $\mathrm{C}_{2}-\mathrm{C}_{4}$ polyols $^{b}$ & Glucose & 5-HMF & Others $^{d}$ & & \\
\hline 1 & None & 0 & 0 & 0 & 0 & 0 & 3.8 & 19.0 & 42.2 & 65.0 & $<0.1$ \\
\hline 2 & $\mathrm{AC}(\mathrm{N})$ & 0 & 0 & 0 & 0 & 0 & 1.5 & 12.8 & 50.6 & 64.9 & $<0.1$ \\
\hline 3 & $\mathrm{Ru} / \mathrm{AC}(\mathrm{N})$ & 33.5 & 9.0 & 42.5 & 0.6 & 6.1 & 0.9 & 0 & $24.3^{h}$ & 74.4 & $15(24)^{j}$ \\
\hline $4^{f}$ & $\mathrm{Ru} / \mathrm{AC}(\mathrm{N})$ & 36.3 & 10.6 & 46.9 & 0.9 & 6.7 & 1.1 & 0 & 29.6 & 85.2 & $15(22)^{j}$ \\
\hline $5^{f}$ & $\mathrm{Ru} / \mathrm{AC}(\mathrm{N})$ & 2.0 & 0.4 & 2.4 & 0 & 0 & 4.4 & 11.6 & 88.6 & 107 & $1.6(46)^{j}$ \\
\hline $6^{g}$ & $\mathrm{Ru} / \mathrm{AC}(\mathrm{N})$ & 29.5 & 8.3 & 37.8 & 1.4 & 6.9 & 0.7 & 0.3 & 35.8 & 82.9 & - \\
\hline 7 & Ru/AC(W) & 18.5 & 4.2 & 22.7 & 0.4 & 4.8 & 1.2 & 0 & 32.7 & 61.8 & $15(45)^{j}$ \\
\hline 8 & Ru/C-Q10 & 36.8 & 9.0 & 45.8 & 1.4 & 5.3 & 0.7 & 0 & 27.0 & 80.2 & $15(22)^{j}$ \\
\hline 9 & Ru/CMK-3 & 35.7 & 9.3 & 45.0 & 1.4 & 7.1 & 0.8 & 0 & 26.9 & 81.2 & $15(23)^{j}$ \\
\hline 10 & Ru/BP2000 & 11.6 & 2.4 & 14.0 & 0.3 & 3.0 & 1.3 & 2.1 & 59.1 & 79.8 & $14(68)^{j}$ \\
\hline 11 & Ru/XC72 & 2.7 & 0.3 & 3.0 & 0.1 & 0 & 1.0 & 1.6 & 72.0 & 77.7 & $8.4(190)^{j}$ \\
\hline 12 & $\mathrm{Ru} / \mathrm{TiO}_{2}$ & 0.1 & 0 & 0.1 & 0 & 0 & 3.5 & 12.8 & 60.0 & 76.4 & 0.6 \\
\hline 13 & $\mathrm{Ru} / \mathrm{ZrO}_{2}$ & 0 & 0 & 0 & 0 & 0 & 2.5 & 13.0 & 62.9 & 78.4 & 0.4 \\
\hline 14 & $\mathrm{Ru} / \mathrm{Al}_{2} \mathrm{O}_{3}$ & 0 & 0 & 0 & 0 & 0 & 2.5 & 14.0 & $55.6^{i}$ & 72.1 & 0.7 \\
\hline $15^{g}$ & $\mathrm{Ru} / \mathrm{Al}_{2} \mathrm{O}_{3}$ & 2.6 & 0.8 & 3.4 & 0 & 6.5 & 0.9 & 0.7 & 65.2 & 76.7 & - \\
\hline 16 & Rh/AC(N) & 0 & 0 & 0 & 0 & 0 & 2.7 & 10.1 & 61.8 & 74.6 & 0.5 \\
\hline 17 & $\mathrm{Ir} / \mathrm{AC}(\mathrm{N})$ & 0 & 0 & 0 & 0 & 0 & 1.3 & 4.6 & 67.9 & 73.7 & 2.3 \\
\hline 18 & Pd/CMK-1 & 0 & 0 & 0 & 0 & 0 & 0.4 & 5.7 & 74.5 & 80.6 & $<0.1$ \\
\hline 19 & Pt/CMK-3 & 0 & 0 & 0 & 0 & 0 & 1.1 & 0 & 80.9 & 82.0 & 4.9 \\
\hline 20 & $\mathrm{Au} / \mathrm{AC}(\mathrm{N})$ & 0 & 0 & 0 & 0 & 0 & 1.6 & 14.6 & 42.6 & 58.8 & 1.4 \\
\hline
\end{tabular}

${ }^{a}$ Cellulose $324 \mathrm{mg}$ (1.90 mmol), catalyst $50 \mathrm{mg}$ (metal $2 \mathrm{wt} \%$ ), water $30 \mathrm{~mL}, 2$-propanol $10 \mathrm{~mL}(130 \mathrm{mmol}), 463 \mathrm{~K}, 18 \mathrm{~h} .{ }^{b}$ Sum of erythritol, glycerine, propylene glycol and ethylene glycol. ${ }^{c} 5$-Hydroxymethyl furfural. ${ }^{d}$ Others include soluble sugar compounds and unidentified ones. ${ }^{e}$ Based on the carbon balance calculated from the weight difference after the reaction. ${ }^{f}$ The reuse experiment using the residue of the experiment of the previous entry number

5 and fresh cellulose of $324 \mathrm{mg}$. The conversion and yields are based on the fresh cellulose. ${ }^{g} \mathrm{H}_{2}$ of $0.8 \mathrm{MPa}$ was used instead of 2 -propanol. Water $40 \mathrm{~mL}$. ${ }^{h}$ Cello-oligosaccharides $1.5 \%$, cellobitol $1.0 \%$, hexanetetrol $4.0 \%$ and unidentified $17.8 \%$ (Fig. S1). ${ }^{i}$ Cello-oligosaccharides $1.9 \%$, fructose $2.3 \%$,

levoglucosan $0.6 \%$, furfural $1.3 \%$ and unidentified $49.5 \% .{ }^{j}$ Ratio of acetone yield against the sugar alcohols yield (mol/mol).

$\mathrm{Ru} / \mathrm{AC}(\mathrm{N})$ as the typical catalyst hereafter because of its significant catalytic activity, good reproducibility and easy 10 availability of the support. ${ }^{11}$

Reuse experiments of $\mathrm{Ru} / \mathrm{AC}(\mathrm{N})$ were performed to verify its durability. The catalyst was separated by centrifugation from the reaction mixture and reused after drying at $383 \mathrm{~K}$. The yields of sorbitol and mannitol were $36 \%$ and $11 \%$, 15 respectively, in the second use (entry 4), which were almost the same as those in the first run (sorbitol 34\%, mannitol 9.0\%). However, the catalyst was deactivated in the third run (entry 5). EDX and XRD analyses of the spent catalyst showed no change of the catalyst after the third use. Thus, the 20 deactivation might be due to the strong adsorption of byproducts on the active sites. The catalyst was usable twice and total TON of Ru for the production of the sugar alcohols was 170 in the reactions. In addition, the filtrate separated by polytetrafluoroethylene (PTFE) membrane $(0.1 \mu \mathrm{m}$ pore) after 25 the first reaction was completely inactive for the transfer hydrogenation. Accordingly, we conclude that $\mathrm{Ru} / \mathrm{AC}(\mathrm{N})$ is a heterogeneous catalyst for the transfer hydrogenation.

As described above, $\mathrm{H}_{2}$ was produced during the transfer hydrogenation reactions, whose partial pressure reached 0.8 ${ }_{30} \mathrm{MPa}$ in the closed reactor from the chemical equilibrium (Eq. 1) at $463 \mathrm{~K}$ in the initial period of $0.5 \mathrm{~h}$. It is noteworthy that the reduction of the dead volume in the reactor decreases the evolution of $\mathrm{H}_{2}$ and improves the utilisation efficiency of 2propanol as the equilibrium shifts to the left-hand side. ${ }_{35}$ Considering this phenomenon, we expected that the hydrogenation of cellulose would proceed at a $\mathrm{H}_{2}$ pressure as low as $0.8 \mathrm{MPa}$ without 2-propanol by using $\mathrm{Ru} / \mathrm{AC}(\mathrm{N})$ catalyst. In fact, the reaction gave good yields of the sugar alcohols (sorbitol 30\%, mannitol 8.3\%, entry 6), whereas ${ }_{40} \mathrm{Ru} / \mathrm{Al}_{2} \mathrm{O}_{3}$, which is a typical active catalyst for the hydrogenation of cellulose with $\mathrm{H}_{2}$ of $5 \mathrm{MPa}$, was significantly less active (sorbitol 2.6\%, mannitol 0.8\%, entry 15) under the same reaction conditions. This result indicates that the active species of $\mathrm{Ru} / \mathrm{AC}(\mathrm{N})$ is different from that of ${ }_{45} \mathrm{Ru} / \mathrm{Al}_{2} \mathrm{O}_{3}$.

$$
\left(\mathrm{CH}_{3}\right)_{2} \mathrm{CH}-\mathrm{OH} \Leftrightarrow\left(\mathrm{CH}_{3}\right)_{2} \mathrm{C}=\mathrm{O}+\mathrm{H}_{2}
$$

To identify the active species for the transfer hydrogenation, $50 \mathrm{XRD}$ analysis was performed for $\mathrm{Ru} / \mathrm{AC}(\mathrm{N})$ and $\mathrm{Ru} / \mathrm{Al}_{2} \mathrm{O}_{3}$. Fig. 1 represents the XRD patterns of $A C(N), R u / A C(N)$ and the differential pattern of $\mathrm{Ru} / \mathrm{AC}(\mathrm{N})$ minus $\mathrm{AC}(\mathrm{N})$. AC(N) gave a broad scattering pattern of amorphous carbon $\left(2 \theta=23^{\circ}\right.$, $43^{\circ}$ and $80^{\circ}$ ) and sharp diffraction peaks of quartz, which is 55 an impurity of AC(N) [Fig. 1(a)]. After the impregnation of $\mathrm{Ru}$, no diffraction peaks of $\mathrm{Ru}$ metal appeared in the XRD [Fig. 1(b, c)], even when the Ru loading was increased to 10 wt\% (Fig. S2). These data show that the Ru species on AC(N) was highly dispersed and/or not fully reduced to zero-valent ${ }_{60}$ particles during the catalyst preparation. We performed $\mathrm{H}_{2}$ temperature programmed reduction (TPR) of Ru/AC(N) (Fig. S3), and 4 peaks appeared at 410, 530, 670 and $860 \mathrm{~K}$ with the $\mathrm{H} / \mathrm{Ru}$ atomic ratios of $13,3.5,2.9$ and 11 , respectively. The second or the third peaks might be assigned to the reduction ${ }_{65}$ of the Ru species by correlating the peak areas with the Ru concentration, suggesting tri- or tetra-valent $\mathrm{Ru}$. Other peaks are due to the reduction of the surface functional groups on the carbon support such as quinones and aromatic rings. In the XPS analysis, the electron binding energy of Ru $3 \mathrm{p}_{3 / 2}$ for 


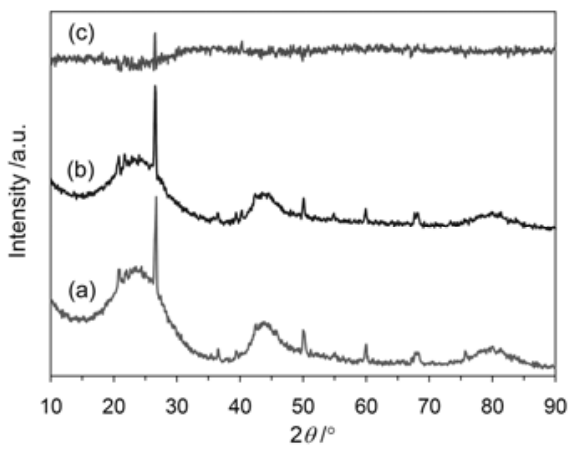

Fig. 1 XRD patterns of (a) $\mathrm{AC}(\mathrm{N})$, (b) $\mathrm{Ru} / \mathrm{AC}(\mathrm{N})$ and (c) the differential pattern of (b)-(a).

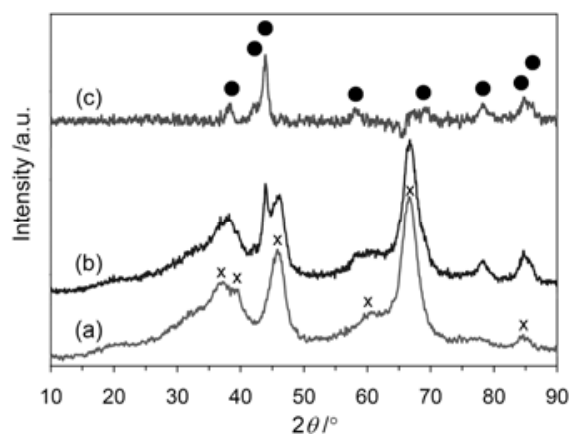

5 Fig. 2 XRD patterns of (a) $\mathrm{Al}_{2} \mathrm{O}_{3}$, (b) $\mathrm{Ru} / \mathrm{Al}_{2} \mathrm{O}_{3}$ and (c) the differential pattern of (b)-(a). Circles: Ru metal. $\mathrm{x}: \gamma-\mathrm{Al}_{2} \mathrm{O}_{3}$.

$\mathrm{Ru} / \mathrm{AC}(\mathrm{N})$ catalyst was $463.1 \mathrm{eV}$, which is in the range of trito tetra-valent states and higher than that for Ru metal (461.9 eV, Fig. S4). Fig. S5 shows the curve fitting of the XPS data 10 for $\mathrm{Ru} / \mathrm{AC}(\mathrm{N})$, and the spectrum was fitted by those of $\mathrm{RuO}_{2}$ (99.7\%) and Ru metal (0.3\%), giving a similar electron state to that of $\mathrm{RuO}_{2}$. It is thus indicated that the $\mathrm{Ru}$ species on $\mathrm{AC}(\mathrm{N})$ is not metal but tetra- or tri-valent. Fig. 2 shows the XRD patterns of $\mathrm{Al}_{2} \mathrm{O}_{3}, \mathrm{Ru} / \mathrm{Al}_{2} \mathrm{O}_{3}$ and the differential pattern 15 of $\mathrm{Ru} / \mathrm{Al}_{2} \mathrm{O}_{3}$ minus $\mathrm{Al}_{2} \mathrm{O}_{3}$. The pattern of $\mathrm{Al}_{2} \mathrm{O}_{3}$ indicated the presence of $\gamma-\mathrm{Al}_{2} \mathrm{O}_{3}$ phase [Fig. 2(a)]. After the loading of $\mathrm{Ru}$, the diffraction pattern of $\mathrm{Ru}$ metal was observed with the peaks of $\gamma-\mathrm{Al}_{2} \mathrm{O}_{3}$ [Fig. 2(b)]. The differential pattern [Fig. 2(c)] clearly showed the peaks of $\mathrm{Ru}$ metal, marked with 20 black circles. The mean diameter of Ru particles was $9 \mathrm{~nm}$, calculated by the Scherrer's equation, which was reported as the best particle size for the selective hydrogenation of cellobiose using $\mathrm{H}_{2}$ of $5 \mathrm{MPa} .^{12}$ Therefore, we conclude that the highly dispersed cationic $\mathrm{Ru}$ species is active for the 25 transfer hydrogenation reaction, whereas $\mathrm{Ru}$ metal nanoparticles are inactive for this reaction.

In summary, $\mathrm{Ru} / \mathrm{AC}(\mathrm{N}), \mathrm{Ru} / \mathrm{C}-\mathrm{Q} 10$ and $\mathrm{Ru} / \mathrm{CMK}-3$ catalysts were active for the transfer hydrogenation of cellulose to sugar alcohols. $\mathrm{Ru} / \mathrm{AC}(\mathrm{N})$ also catalysed the 30 hydrogenation of cellulose at a $\mathrm{H}_{2}$ pressure as low as $0.8 \mathrm{MPa}$. The catalytic activity of $\mathrm{Ru} / \mathrm{AC}(\mathrm{N})$ is significantly different from those of the typical catalysts for the cellulose hydrogenation such as $\mathrm{Ru} / \mathrm{Al}_{2} \mathrm{O}_{3}$, which require high pressures of $\mathrm{H}_{2}$. It is proposed that the active species for the transfer 35 hydrogenation is a cationic Ru species.

We thank Prof. W. Ueda for the $\mathrm{H}_{2}$-TPR study. This work was financially supported by JSPS KAKENHI (20226016).

\section{Notes and references}

${ }^{a}$ Catalysis Research Centre, Hokkaido University, Kita 21 Nishi 10, Kita40 ku, Sapporo 001-0021, Japan. Fax: (+81) 11706 9139; E-mail:

fukuoka@cat.hokudai.ac.jp

${ }^{b}$ Division of Chemical Sciences and Engineering, Graduate School of

Chemical Sciences and Engineering, Hokkaido University, Kita 13 Nishi

8, Kita-ku, Sapporo 060-8628, Japan.

$45 \dagger$ Electronic Supplementary Information (ESI) available: [analysis methods of products, characterisation procedures of the catalysts, XRD, $\mathrm{H}_{2}$-TPR, XPS, optimisation of the reaction]. See DOI: 10.1039/b000000x/ ¥ The catalyst supports used in this study are as follows. CMK-1 and CMK-3 were synthesised according to procedures in the literature. ${ }^{13}$ 50 Carbon (C-Q10, BET surface area $840 \mathrm{~m}^{2} \mathrm{~g}^{-1}$ ) was prepared using an amorphous silica (Q-10, Fuji Silysia) in the same manner as for CMK-3. Activated carbons were purchased from Wako (activated charcoal), denoted as AC(W) and Aldrich (SX Ultra, Norit), denoted as AC(N). Carbon blacks (VULCAN XC72 and BP2000) were supplied from Cabot.

55 Other supports are $\mathrm{TiO}_{2}$ (P-25, Degussa), $\mathrm{ZrO}_{2}$ (JRC-ZRO-2, Catalysis Society of Japan) and $\mathrm{Al}_{2} \mathrm{O}_{3}$ (JRC-ALO-2, Catalysis Society of Japan).

Supported $\mathrm{Ru}$ catalysts (Ru metal loading $2 \mathrm{wt} \%$ ) were prepared by a conventional impregnation method as follows: $\mathrm{RuCl}_{3}$ aq. $(0.202 \mathrm{mmol}$ in $5 \mathrm{~mL}$ of water) was dropped into a mixture of a catalyst support (1.00 g) 60 and water $(20 \mathrm{~mL})$, and the mixture was stirred for $16 \mathrm{~h}$. After drying in vacuo, the solid was reduced in a fixed-bed flow reactor with $\mathrm{H}_{2}(30 \mathrm{~mL}$ $\mathrm{min}^{-1}$ ) at $673 \mathrm{~K}$ for $2 \mathrm{~h}$. In the cases using oxide supports, the precursors

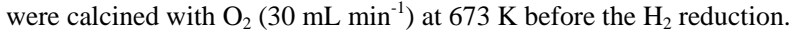

Transfer hydrogenation of cellulose was carried out in a stainless steel 65 (SUS316) high-pressure reactor (OM Lab-Tech MMJ-100, $100 \mathrm{~mL}$ ). Cellulose (Merck, Avicel) was milled using $\mathrm{ZrO}_{2}$ balls at $60 \mathrm{rpm}$ for 4 days. The milled cellulose (324 mg, $1.90 \mathrm{mmol}$ glucose units, containing $4.8 \mathrm{wt} \%$ physisorbed water), supported $\mathrm{Ru}$ catalyst (50 mg), water (30 $\mathrm{mL})$ and 2-propanol $(10 \mathrm{~mL})$ were charged in the reactor (glucose unit/Ru $70=190$ ), and then purged with $1 \mathrm{~atm}$ of $\mathrm{N}_{2}$ or He. The mixture was heated to $463 \mathrm{~K}$ and maintained at this temperature for $18 \mathrm{~h}$ with stirring at 600 rpm. The analysis methods of products and the characterisation procedures of the catalysts are described in the ESI.

1 J. N. Chheda, G. W. Huber and J. A. Dumesic, Angew. Chem. Int. Ed., 2007, 46, 7164.

2 D. Klemm, B. Heublein, H.-P. Fink and A. Bohn, Angew. Chem. Int. Ed., 2005, 44, 3358.

3 P. L. Dhepe and A. Fukuoka, ChemSusChem, 2008, 1, 969-975; R. Rinaldi and F. Schüth, ChemSusChem, 2009, 2, 1096.

804 S. Deguchi, K. Tsujii and K. Horikoshi, Chem. Commun., 2006, 3293.

5 A. Fukuoka and P. L. Dhepe, Angew. Chem. Int. Ed., 2006, 45, 5161.

6 a) C. Luo, S. Wang and H. Liu, Angew. Chem. Int. Ed., 2007, 46, 7636; b) W. Deng, X. Tan, W. Fang, Q. Zhang and Y. Wang, Catal. Lett., 2009, 133, 167; c) S. Van de Vyver, J. Geboers, M. Dusselier,

85 H. Schepers, T. Vosch, L. Zhang, G. Van Tendeloo, P. A. Jacobs and B. F. Sels, ChemSusChem, 2010, 3, 698; d) L. Ding, A. Wang, M. Zheng and T. Zhang, ChemSusChem, 2010, 3, 818.

7 N. Ji, T. Zhang, M. Zheng, A. Wang, H. Wang, X. Wang and J. G. Chen, Angew. Chem. Int. Ed., 2008, 47, 8510; M. Zheng, A. Wang, N.

90 Ji, J. Pang, X. Wang and T. Zhang, ChemSusChem, 2010, 3, 63; Y. Zhang, A. Wang and T. Zhang, Chem. Commun., 2010, 46, 862.

8 V. Jollet, F. Chambon, F. Rataboul, A. Cabiac, C. Pinel, E. Guillon and N. Essayem, Green Chem., 2009, 11, 2052.

9 H. Kobayashi, T. Komanoya, K. Hara and A. Fukuoka, ChemSusChem, 2010, 3, 440.

10 W. L. Marshall and E. U. Franck, J. Phys. Chem. Ref. Data, 1981, 10, 295.

11 The optimisation of the reaction conditions using $\mathrm{Ru} / \mathrm{AC}(\mathrm{N})$ catalyst is shown in the ESI: effect of the concentration of 2-propanol (Table S1), screening of the hydrogen source (Table S2).

12 W. Deng, M. Liu, X. Tan, Q. Zhang and Y. Wang, J. Catal., 2010, 271, 22.

13 R. Ryoo, S. H. Joo and S. Jun, J. Phys. Chem. B, 1999, 103, 7743; S. Jun, S. H. Joo, R. Ryoo, M. Kruk, M. Jaroniec, Z. Liu, T. Ohsuna and O. Terasaki, J. Am. Chem. Soc., 2000, 122, 10712. 